\title{
The Sainte-Laguë index of disproportionality and Dalton's principle of transfers
}

Josh Goldenberg

University of Oxford
Stephen D. Fisher

University of Oxford

Accepted for publication in Party Politics, March 2017. 』

\begin{abstract}
The Sainte-Laguë index has a strong claim to be the index that should be adopted as the standard measure of disproportionality in electoral studies. Its properties are therefore worthwhile understanding more clearly. This paper provides a counter-example (the 2010 UK general election) to previous claims that the Sainte-Laguë index satisfies Dalton's principle of transfers with respect to differences between seat shares and vote shares, but not ratios of seat and vote shares. Instead, we prove that the Sainte-Lague index satisfies the ratio but not the difference version of the principle. This strengthens the argument for the Sainte-Lague index since the ratio version is the one that accords with notion of electoral disproportionality as inequality the in representation of voters.
\end{abstract}

\section{INTRODUCTION}

The Sainte-Lague index is a measure of disproportionality of parliamentary seat allocation relative to the distribution of votes across parties in an election. There are many alternative indices of disproportionality. Most commonly used is the Gallagher index, which Michael Gallagher himself referred to as the least-squares index in the paper where he first identified it (Gallagher, 1991). That paper did not advocate what came to be known as the Gallagher index. Instead the conclusion includes the following remarks.

Of the various measures based on the largest remainders method, the least squares index seems to have advantages over the more widely used Loosemore-Hanby and Rae indices. Among the indices based on highest average methods, Sainte-Laguë's has clear merits when compared with indices based on the d'Hondt method. Its invulnerability to the

Contact. stephen.fisher@trinity.ox.ac.uk (Fisher) and jmrgoldenberg@gmail.com (Goldenberg).

Acknowledgements. We thank Alan Renwick and two anonymous referees for helpful comments on earlier versions of this paper. 
paradoxes to which the measures based on largest remainders are susceptible is a strong argument in favour of its adoption as the standard measure of disproportionality. (p.49)

Despite this, the least-squares (Gallagher) index has become industry standard for electoral analysis because of studies comparing it favourably with others (Lijphart, 1994; Monroe, 1994; Taagepera and Grofman, 2003). More recently Renwick (2015) has provided a powerful argument for reviving the use of the Sainte-Laguë index. As part of his argument he refers to the analysis of properties of various disproportionality indices by Taagepera and Grofman (2003) in this journal. Renwick (2015) points out that he does not think it matters much that the Sainte-Laguë index does not satisfy the three criteria which Taagepera and Grofman identify the Sainte-Laguë index as falling short on. Otherwise there is much to recommend it.

The purpose of this paper is to contribute to the debate about the relative merits of different indices by correcting a misunderstanding about the properties of the SainteLaguë index with respect to Dalton's principle of transfers. This generally accepted condition requires that if a seat is transferred from a more richly represented party to a less richly represented party, without changing the order of richness of representation, then the index of disproportionality should go down (in the strong version of the principle) or at least not increase (the weak version).

Taagepera and Grofman (2003) rightly point out that there is an ambiguity as to what counts as richer representation. Does it refer to the difference between seat share and vote share (seats minus votes) or does it mean the ratio of seats to votes (seats divided by votes) is bigger? Whether or not an index complies with Dalton's principle of transfers depends on whether it is being judged based on differences or ratios of seats and votes.

This is not surprising given what we know from Gallagher (1991). Different disproportionality indices measure different kinds of disproportionality. Some are based on differences (often and in the above quote referred to as 'remainders') and some based on ratios (sometimes and in the above quote referred to as 'averages'). Naturally the ones based on differences are more likely to comply with the principle of transfers 
expressed in terms of differences between seats and votes, and similarly for ratios. To some extent it would be unfair to judge an index designed to measure disproportionality using differences with the principle expressed in terms of ratios, and vice versa.

Taagepera and Grofman (2003) go on to claim that the Sainte-Laguë index satisfies Dalton's principle of transfers expressed in terms of differences but not when it is expressed in terms of ratios. The main purpose of this paper is to prove that the opposite is the case. The Sainte-Laguë index satisfies Dalton's principle of transfers expressed in terms of ratios but not when it is expressed in terms of differences. We derive a proof of the former claim, and provide a counterexample (the $2010 \mathrm{UK}$ general election) as proof of the latter.

Before turning to the proofs we first formally define the Sainte-Laguë index and discuss competing views of Dalton's principle. In particular we note that Van Puyenbroeck (2008) shows how the ratio version of the principle must be adopted if disproportionality is to be thought of as measuring inequality between voters. Thus our proofs strengthen the argument for use of the Sainte-Laguë index to measure electoral disproportionality. The paper concludes with some further reflections on why it is important to be clear on the ways in which indices do or do not comply with Dalton's principle of transfers.

\section{THE SAINTE-LAGUË INDEX}

The Sainte-Laguë index of disproportionality (SLI) focusses on the ratio between the seat share $\left(s_{i}\right)$ and vote share $\left(v_{i}\right)$ for each party $i$ (which we will view as percentages), in particular the ratio $s_{i} / v_{i}$. In a perfectly proportional outcome, then $s_{i} / v_{i}=1$ for each $i$. As Gallagher (1991) describes, $\left|\frac{s_{i}}{v_{i}}-1\right|$ is considered as an error term for each party, which is squared, weighted by the vote share $v_{i}$ so that ultimately voters are treated equally, before summing across parties. Thus the Sainte-Laguë index is defined as,

$$
S L I=\sum_{i=1}^{n} v_{i}\left(\frac{s_{i}}{v_{i}}-1\right)^{2}=\sum_{i=1}^{n} \frac{\left(s_{i}-v_{i}\right)^{2}}{v_{i}}
$$


Taagepera and Grofman (2003) refer to this as the $\chi^{2}$ index because of the similarity with Pearson's $\chi^{2}$ statistic. However, the motivation that leads to SLI is very different to $\chi^{2}$. Both are measures of goodness of fit - in the current context goodness of fit of an election outcome to perfect proportionality. The analogy with Pearson's $\chi^{2}$ statistic comes by viewing $\frac{\left(s_{i}-v_{i}\right)^{2}}{v_{i}}$ as $\frac{\left(O_{i}-E_{i}\right)^{2}}{E_{i}}$, where we observe seat shares $(\mathrm{O})$ and consider the expected seat shares $(\mathrm{E})$ to be equal to the vote shares under perfect proportionality. This is a reasonable way of thinking about SLI, but it does not reflect the notion of measuring ratios of seats to votes that was the basis of the derivation that Sainte-Laguë (1910) provided (see Lijphart and Gibberd (1977, pp.241-2) for an English translation). Van Puyenbroeck (2008) further helps clarify how minimisation of the Sainte-Laguë index constitutes minimisation of inequality between voters.

\section{DALTON'S PRINCIPLE OF TRANSFERS}

Dalton's principle of transfers (Dalton, 1920) specifies an important property for any index of disproportionality. It states that if one party is better represented (or less under-represented) than another and seats are transferred from the better represented party to the other, without changing which party is better represented, the index of disproportionality will decrease (and vice versa). The basic idea is that it should be possible to make a disproportional result more proportional by transferring seats from a more richly represented party to one less well represented, so long as the number of seats transferred does not change the ordering of the two parties involved in terms of how richly represented they are. (If the order does change then the result might become more disproportional in a different direction.)

The principle has its intellectual origins in debates about the measurement of inequality from the economics literature (Dalton, 1920; Pigou, 1920). In that context the intuition is clear - inequality declines if money is transferred from someone richer to someone poorer. In an electoral context the transfer principle seems to have been accepted both because scholars sometimes view disproportionality as an issue of inequality and as an intuitively appealing idea to apply to election results on its own terms (e.g. Monroe, 1994; Fry and McLean, 1991). 
Taagepera and Grofman (2003, p.667-8) rightly note the ambiguity about what it means for a party to be more well-off or more overrepresented. Is a party with $50 \%$ of the vote and $70 \%$ of the seats better represented than a party with $10 \%$ of the vote and $20 \%$ of the seats? In difference terms yes, but in relative terms no. (The latter party has twice the proportional number of seats, as opposed to 1.4 times for the former party.)

Taagepera and Grofman argue that in an electoral context the difference interpretation should "probably" be preferred to the ratio interpretation because, "its the number of extra seats for a large party that matters in ease of cabinet formation, rather than a large relative excess for a small party that still remains small." This seems to us to be misplaced as an argument because it is not based on considerations of what constitutes disproportionality, rather something that disproportionality might affect. Moreover, Taagepera and Grofman go on to temper their view by expressing concern about violating the ratio version before remarking, "Maybe this is the crucial difference between the notions of 'deviation from proportionality' (stressing the difference) and 'inequality' (stressing the ratio)."

Van Puyenbroeck (2008) picks up on this idea but does not reach such an equivocal conclusion. He shows that measures based on differences in vote and seat shares cannot coherently not be thought of as measures of inequality, either between voters or between parties. Voters are equally represented if the number of legislators from a party per voter for that party is the same for each party, i.e. the ratios $s_{i} / v_{i}$ are the same for all $i$. Van Puyenbroeck explains how, if disproportionality is about inequality in the political representation of voters, then the only valid version of the Dalton principle is the ratio one.

This constitutes a powerful argument for preferring the ratio version, but it depends on conceptualising disproportionality as inequality in the representation of voters. The difference version is still coherent and intuitively attractive on its own terms and so may still be of interest to readers willing to give up on the idea that a measure of disproportionality is a measure of inequality. For this reason we do not dismiss the difference version entirely. 
Taagepera and Grofman (2003) wrongly claim (in the final line of p.667) that the Sainte-Laguë index satisfies the principle of transfers expressed in terms of differences between seats and votes. To show why this claim is false Table 1 provides details of a counterexample taken from the UK general election of $20103^{3}$

TABLE 1. UK general election of 2010 as a counterexample to the claim that the Sainte-Lague index satisfies Dalton's principle of transfers with the difference interpretation

\begin{tabular}{lrrrrrr}
\hline & \multicolumn{3}{l}{ Actual results: A } & \multicolumn{3}{c}{ One seat transfer from Con to Lab: B } \\
\cline { 2 - 7 } & \multicolumn{3}{c}{ SLI contribution } \\
$\left(s_{i}-v_{i}\right)^{2} / v_{i}$ & $v_{i}$ & $s_{i}$ & $\begin{array}{r}\text { SLI contribution } \\
\left(s_{i}-v_{i}\right)^{2} / v_{i}\end{array}$ \\
Party & $v_{i}$ & $s_{i}$ & 3.37 & 36.05 & 46.92 & 3.28 \\
\hline Conservative & 36.05 & 47.08 & 3.95 & 28.99 & 39.85 & 4.07 \\
Labour & 28.99 & 39.69 & 13.50 & 34.96 & 13.23 & 13.50 \\
Others & 34.96 & 13.23 & 20.82 & 100.00 & 100.00 & 20.84 \\
\hline Total & 100.00 & 100.0 & &
\end{tabular}

Note: Authors' own calculations based on vote and seat totals from Rallings and Thrasher (2012, p.60)

Table 1 considers a hypothetical transfer of one seat from the Conservatives to Labour and how this would change SLI from the actual results (election A) after the hypothetical transfer (election B). ${ }_{4}^{4}$ In difference terms the Conservatives were more richly represented than Labour in both elections: $47.08-36.05>39.69-28.99$ and $46.92-36.05>39.85-28.99$. So the transfer is from the most richly to a less richly represented party without changing the order of representation. As can be seen from the SLI contribution columns, the lesser over-representation of the Conservatives after the transfer decreases its contribution to the Sainte-Laguë index. However this decrease is more than offset by an increase in the contribution from Labour. The overall SLI, in the bottom row, increases from 20.82 to 20.84 despite the transfer of a seat from a more overrepresented party to a party that is less overrepresented. This counterexample thus constitutes a proof that the Sainte-Laguë index does not satisfy Dalton's principle of transfers when proportionality is interpreted in terms of differences between seats and votes.

\footnotetext{
${ }^{3}$ Lumping other parties together in this way is not valid for the calculation of SLI, but that aspect is irrelevant for illustrating the effect of a transfer from the Conservatives to Labour.

${ }^{4}$ Calculations are exact but figures presented in the table are rounded. One seat out of 650 is approximately 0.154 percentage points.
} 
The change in SLI in Table 1 is only modestly in the wrong direction. It is possible to construct other clearer examples with more substantial changes in the wrong direction but they would be less obviously realistic. The outcome of the UK 2010 general election was chosen so that it cannot be dismissed as a mere technicality. It really was the case SLI would have been larger had Labour gained one more seat at the expense of the Conservatives on the same vote shares.

It is worth noting that the scenario in Table 1 is one in which the transfer increases inequality and disproportionality if proportionality is understood not in terms of differences but ratios of seats to votes. With ratios of seats to votes Labour is the most over-represented party: $\frac{39.69}{28.99}>\frac{47.08}{36.04}$ and $\frac{39.85}{28.99}>\frac{46.92}{36.04}$. So with relative disproportionality the transfer is to the most from a less well represented party, and the SainteLaguë index goes up. Thus SLI seems to satisfy Dalton's principle of transfers in this particular case if proportionality is interpreted in terms of ratios.

But is this true generally? Taagepera and Grofman (2003) claim (in the penultimate row of their Table 2) that it is not. However, we offer the following formal theorem and proof that the Sainte-Laguë index does comply with Dalton's principle of transfers when proportionality is interpreted in terms of ratios of seats to votes.

Theorem: Suppose there are two parties, 1 and 2, such that party 1 is better represented (in relative terms) than party 2 -i.e. $s_{1} / v_{1}>s_{2} / v_{2}$. If we transfer $\varepsilon>0$ seats to party 2 from party 1 , without changing the order of richness of representation (i.e. $\left.\left(s_{1}-\varepsilon\right) / v_{1} \geq\left(s_{2}+\varepsilon\right) / v_{2}\right)$, then these new vote-seat distributions will contribute less to SLI than before the transfer and SLI will decline.

Proof. We can rewrite the two conditions as:

$$
\begin{aligned}
s_{1} / v_{1}>s_{2} / v_{2} & \Leftrightarrow s_{1} v_{2}>s_{2} v_{1} \\
& \Leftrightarrow s_{2} v_{1}-s_{1} v_{2}<0
\end{aligned}
$$


and

$$
\begin{aligned}
\left(s_{1}-\varepsilon\right) / v_{1} \geq\left(s_{2}+\varepsilon\right) / v_{2} & \Leftrightarrow s_{1} v_{2}-\varepsilon v_{2} \geq s_{2} v_{1}+\varepsilon v_{1} \\
& \Leftrightarrow s_{2} v_{1}-s_{1} v_{2}+\varepsilon\left(v_{1}+v_{2}\right) \leq 0 .
\end{aligned}
$$

We define the new seat distributions as $s_{1}^{*}=s_{1}-\varepsilon, s_{2}^{*}=s_{2}+\varepsilon$, and we denote the value of SLI contributed from the two parties with this transfer as $S L I_{1,2}^{*}$, and similarly denote the contribution of the two parties without the transfer as $S L I_{1,2}$. We have

$$
\begin{aligned}
& S L I_{1,2}^{*}=\left(v_{1}-s_{1}^{*}\right)^{2} / v_{1}+\left(v_{2}-s_{2}^{*}\right)^{2} / v_{2} \\
& =\left(\left(v_{1}-s_{1}\right)+\varepsilon\right)^{2} / v_{1}+\left(\left(v_{2}-s_{2}\right)-\varepsilon\right)^{2} / v_{2} \\
& =\left(\left(v_{1}-s_{1}\right)^{2}+\varepsilon\left(2 v_{1}-2 s_{1}+\varepsilon\right)\right) / v_{1}+\left(\left(v_{2}-s_{2}\right)^{2}+\varepsilon\left(2 s_{2}-2 v_{2}+\varepsilon\right)\right) / v_{2} \\
& =\left(v_{1}-s_{1}\right)^{2} / v_{1}+\left(v_{2}-s_{2}\right)^{2} / v_{2}+\varepsilon\left(v_{2}\left(2 v_{1}-2 s_{1}+\varepsilon\right)+v_{1}\left(2 s_{2}-2 v_{2}+\varepsilon\right)\right) / v_{1} v_{2} \\
& =S L I_{1,2}+\varepsilon\left(2 v_{1} v_{2}-2 v_{1} v_{2}+2\left(s_{2} v_{1}-s_{1} v_{2}\right)+\varepsilon\left(v_{1}+v_{2}\right)\right) / v_{1} v_{2} \\
& =S L I_{1,2}+\varepsilon\left(2\left(s_{2} v_{1}-s_{1} v_{2}\right)+\varepsilon\left(v_{1}+v_{2}\right)\right) / v_{1} v_{2} \\
& <S L I_{1,2}+\varepsilon\left(\left(s_{2} v_{1}-s_{1} v_{2}\right)+\varepsilon\left(v_{1}+v_{2}\right)\right) / v_{1} v_{2} \quad \text { (by equation (2) and as } \varepsilon>0 \text { ) } \\
& \leq S L I_{1,2}+\varepsilon \times 0 / v_{1} v_{2} \quad \text { (by equation (3) and as } \varepsilon>0 \text { ) } \\
& =S L I_{1,2} \text {. }
\end{aligned}
$$

As the contributions from all other parties are the same before and after the transfer, as nothing has changed for them, $S L I^{*}<S L I$ as required.

\section{OTHER INDICES AND DALTON'S PRINCIPLE OF TRANSFERS}

It is not our intention to go into depth here about which other indices do and do not comply with Dalton's principle of transfers. However, we do note that it follows from the fact that SLI does not satisfy the difference version of the principle of transfers that Taagepera and Grofman (2003) are also mistaken in this respect about two other indices that are strongly related to the Sainte-Laguë index. These are what they call the Chi-square-based probability $=1-p\left[t<\chi^{2}(n)\right]$, and $L_{2}=\left(\frac{S}{V}\right)^{2} \sum \frac{\left(s_{i}-v_{i}\right)^{2}}{v_{i}^{2}}$. The former is a monotone function of SLI, so any transfer that decreases SLI must 
simultaneously also decrease the Chi-squared-based probability. The latter is the same as SLI when votes and seats are measured in proportions or percentages except that the divisor is $v_{i}^{2}$ instead of $v_{i}$. This means it behaves similarly with respect to transfers but even more emphatically in the same direction. So for both these indices Taagepera and Grofman (2003) are wrong in saying that they satisfy the difference version (bottom of p.667) and do not satisfy the ratio version of Dalton's principle of transfers (their Table 2) $!^{5}$

Regarding the most commonly used indices of disproportionality, Taagepera and Grofman (2003) were right to say that Gallagher's (least-squares) index satisfies the strong version of the principle expressed in terms of seats-votes differences. They also rightly point out that the Loosemore-Hanby index only satisfies the weak version whereby the index does not necessarily drop but definitely does not increase after a transfer of seats from a richer to a poorer represented party. This is because the Loosemore-Hanby index is insensitive to transfers between over-represented parties or between under-represented parties. The failure of the Gallagher and LoosemoreHanby indices to comply with the ratio version of Dalton's principle weakens their value because they do not measure inequality between voters.

\section{CONCLUSion}

We have shown that, contrary to claims made by Taagepera and Grofman (2003), the Sainte-Laguë index satisfies Dalton's principle of transfers when disproportionality is thought of in terms of ratios but not differences in seat and vote shares. Perhaps part of the reason Taagepera and Grofman (2003) came to be mistaken about this is their view of the Sainte-Laguë index as fundamentally based on squares of differences. This makes sense if the index is being viewed primarily by analogy with Pearson's $\chi^{2}$ statistic. But, as we discussed in the section on the definition of SLI, if viewed in terms of the first form in equation 1 and in line with Sainte-Laguë's original derivation, the index is about measuring disproportionality with respect to ratios. True, the index is based on squared differences between ratios, rather than ratios of

\footnotetext{
${ }^{5}$ Our hypothetical scenario in Table 1 also works as a counter example for the claim that the Chisquared-based probability and $L_{2}$ satisfy the difference version.
} 
ratios, but this does not change the fundamental rationale for the index as a measure of disproportionality in relative terms.

The practical relevance of deciding which version of the Dalton principle to use is illustrated in this paper with the 2010 UK general election. That provides a realworld instance of when Dalton's transfer principle works with respect to ratios but not differences. Only a ratio based measure of disproportionality, such as SLI, is it possible to say that the transfer of a seat from the Conservatives to Labour would have worsened inequality. Such a transfer increases the Gallagher and LoosemoreHanby indices. Whether this is the right conclusion to reach about 2010 depends on the crucial normative and conceptual question of what disproportionality is, and in particular whether electoral disproportionality should reflect the degree of inequality in voter representation.

This issue needs a much fuller discussion than has been provided here or in the existing literature. But this paper, and especially our discussion of the various arguments from Taagepera and Grofman (2003) and Van Puyenbroeck (2008), shows how pivotal is the issue of disproportionality as inequality. If this notion is at all attractive then the ratio version of Dalton's principle has the advantage of being consistent with the idea of disproportionality as inequality. Using the difference version means giving up on this, without any compensating powerful argument to do so. Thus in showing that the Sainte-Laguë index satisfies the ratio version of the Dalton principle we have strengthened the argument for its greater use. Conversely, the case for the two most used indices, Loosemore-Hanby and Gallagher, is now weaker because these only satisfy the difference version of the Dalton principle.

More generally, this paper helps to emphasise that the properties of indices of disproportionality are still not adequately understood and more careful consideration of the distinction between relative and absolute disproportionality is needed. As a further and more profound example of this need, note that the Gallagher index came to prominence largely thanks to Lijphart's (1994) advocacy. But recently Renwick (2015) has shown that Lijphart failed to consider the Sainte-Laguë index when arguing in 
favour of a difference based measure of disproportionality against ratio based measures. Lijphart's arguments were against D'Hondt ratios but Renwick points out that they do not apply to the Sainte-Laguë approach. Renwick's compelling case for reconsideration of the somewhat neglected Sainte-Laguë index means we need a sounder understanding of its properties. This paper contributes to that goal.

\section{REFERENCES}

Dalton, Hugh. 1920. “The Measurement of the Inequality of Incomes." The Economic Journal 30(119):348.

Fry, Vanessa and Iain McLean. 1991. "A note on rose's proportionality index." Electoral Studies 10(1):52-59.

Gallagher, Michael. 1991. "Proportionality, disproportionality and electoral systems." Electoral studies 10(1):33-51.

Lijphart, A and R W Gibberd. 1977. "Thresholds and Payoffs in List Systems of Proportional Representation.” European Journal of Political Research 5:219-244.

Lijphart, Arend. 1994. Electoral Systems and Party Systems. A Study of Twentyseven Democracies, 1945-1990 Oxford: Oxford University Press.

Monroe, Burt L. 1994. "Disproportionality and malapportionment: Measuring electoral inequity.” Electoral Studies 13(2):132-149.

Pigou, A C. 1920. Wealth and Welfare. London: Macmillan.

Rallings, Colin and Michael Thrasher, eds. 2012. British Electoral Facts 1832-2012. London: Biteback Publishing.

Renwick, Alan. 2015. "Electoral Disproportionality: What Is It and How Should We Measure It?" http://bit.ly/1RSUA4a.

Taagepera, Rein and Bernard Grofman. 2003. "Mapping the indices of seats-votes disproportionality and inter-election volatility." Party Politics 9(6):659-677.

Van Puyenbroeck, T. 2008. "Proportional Representation, Gini Coefficients, and the Principle of Transfers." Journal of Theoretical Politics 20(4):498-526. 